Faculty of Education

Te Kura Toi Tangata

Waikato Journal of Education

Te Hautaka Mātauranga o Waikato

Volume 16, Issue 2: 2011 


\section{WAIKATO JOURNAL OF EDUCATION TE HAUTAKA MĀTAURANGA O WAIKATO}

\section{Editors:}

Jane Strachan

Noeline Wright

\author{
Editorial Board: \\ Beverley Bell \\ Bronwen Cowie \\ Deborah Fraser \\ Margie Hohepa \\ Sally Peters \\ Noeline Wright
}

\author{
Margaret Carr \\ Rosemary DeLuca \\ Richard Hill \\ Judy Moreland \\ Clive Pope
}

Waikato Journal of Education is a refereed journal, published annually, based in the Faculty of Education, The University of Waikato, Hamilton, New Zealand. It publishes articles in the broad field of education. For further information visit the WJE website http://edlinked.soe.waikato.ac.nz/research/journal/index.php?id=8

Correspondence and articles for review should be addressed to: Research Manager, Wilf Malcolm Institute of Educational Research, Faculty of Education, The University of Waikato, Private Bag 3105, Hamilton, 3240, New Zealand. Email: wmier@waikato.ac.nz

Business correspondence: Orders, subscription payments and other enquiries should be sent to the Administrator, Waikato Journal of Education, Wilf Malcolm Institute of Educational Research, Faculty of Education, The University of Waikato, Private Bag 3105, Hamilton, 3240, New Zealand, Email: wmier@waikato.ac.nz

Subscriptions: Within NZ \$40; Overseas NZ \$50

Copyright: (C) Faculty of Education, The University of Waikato

Publisher: $\quad$ Faculty of Education, The University of Waikato

Cover design: Donn Ratana

Printed by: Waikato Print

\section{Call for papers}

The Waikato Journal of Education provides an avenue of publication for quality articles on education. This peer-reviewed journal welcomes a range of topics including interdisciplinary, philosophical and applied research approaches.

Submissions are now invited for consideration for publication in the November 2012 issue. Please submit an electronic copy and a separate page with author/s contact details by 30 April 2012 to WMIER Research Manager, Carolyn Jones (cjjones@waikato.ac.nz), Faculty of Education, University of Waikato, Private Bag 3105, Hamilton 3240, New Zealand. 


\section{Waikato Journal of Education}

\section{Te Hautaka Mātauranga o Waikato}

Volume 16, Issue 2: 2011

\section{Special Edition: A teacher education partnership between the Solomon Islands and New Zealand}

Editorial

The Solomon Islands School of Education Partnership: Aspirations, context and design in educational change

Clive McGee and Patricia Rodie

Partnership experiences in developing the Preparation for Tertiary Learning course in the Teachers in Training programme

Roselyn Maneipuri, Immaculate Runialo and Noeline Wright

Making sense of health education in the Solomon Islands

Kirsten Petrie and Mark Tehe

The Solomon Islands mathematics: Pedagogy in transition?

Nigel Calder, John Beuka and Calvin Ngatulu

Taking ownership: The story of a successful partnership for change in a Pacific Island science teacher education setting

Richard Edwards, Solomon Pita and James Porakari

Funds of knowledge: Developing a Diploma in Teaching in Early Childhood Education in the Solomon Islands

Janette Kelly, Joanna Daiwo and Viola Malasa

Weaving a "Hybrid Mat": Samoa meets the Solomons

Barbara Whyte

Sustaining organisational change: Teacher education in the Solomon Islands Jane Strachan, Susanne Maezama and Janine Simi

Exploring factors that influence school planning in community high schools in the Solomon Islands: Principals' perspectives

Samuel Aruhu and David Giles

Experiences of being a leader in Choiseul Province: Opening principals' and deputy principals' contexts of leadership

John Sisiolo and David Giles

Book review 


Waikato Journal of Education
Te Hautaka Mātauranga o
Volume 16 Issue 2: 2011

\title{
The Solomon Islands mathematics: Pedagogy in transition?
}

\author{
Nigel Calder \\ Faculty of Education \\ University of Waikato \\ John Beuka and Calvin Ngatulu \\ School of Education \\ Solomon Islands College of Higher Education
}

\begin{abstract}
This article examines the transition of the Solomon Islands School of Education's primary and secondary mathematics education programme from a focus on content knowledge and teacher transmission, to a more activity-based, problem-solving, learner-centred approach. The ways the development team co-constructed that change so that it incorporated current mathematics education pedagogy, the Solomon Islands' Mathematics Curriculum document, and elements of Solomon Islands mathematics are described. How the team attempted to manage the dilemma between local educational imperatives and the globalisation of mathematics education is considered. Central to this are comparisons with international research on mathematics education pedagogy, while giving recognition to the situating of these within localised contexts.

The article describes the ways the transition evolved, and how issues related to the change process, such as trust, culture, pedagogy and power, were engaged with, both proactively and incidentally. It will also consider lecturer/student reflection on the programme and the ways the changes may have influenced teaching. This article contends that change that is co-constructed and hinged to respectful partner relationships, will lead to greater participant autonomy and enhance the sustainability of the change. Finally, it poses questions that require subsequent examination for the transition to be sustainable.
\end{abstract}

\section{Keywords}

Teacher education, mathematics education, Pacific education, teacher identities, coconstructing curriculum.

Faculty of Education, University of Waikato, Hamilton, New Zealand 


\section{Introduction}

"I'm teaching the same programme I did as a student over twenty years ago!" This comment was followed by howls of laughter by the mathematics education team as we reflected on the current Solomon Islands School of Education (SOE) mathematics programme for pre-service teachers. It was our first face-to-face meeting and the mathematics team was giving an overview of the existing courses and their impression of how they were going. It was a key moment for us all as collectively we realised the need to change, and that there were issues with the existing programme. Critically, it indicated a desire to engage with the change process to better prepare the pre- and inservice teachers in mathematics education, and hence enhance the mathematical thinking and understanding of Solomon Islands children.

The team consisted of the SOE mathematics education team, including the Head of Department, John Beuka, and Nigel Calder, the University of Waikato (UOW) mathematics education staff member for the partnership. Although the Partnership had been intentionally entered into by the SOE and the New Zealand Aid Programme to review and develop the existing pre-service teaching diploma and certificate programmes being offered by the SOE, there were other key elements that informed the team's readiness to engage in the change process and co-construct the new programme. Firstly, the teaching team realised that their programme was not engaging students in mathematics education pedagogy but was predominantly content focused. The SOE mathematics team also felt that there was a general sense of disengagement with the programme, often due to students' personal negative mathematical experiences in the case of the primary teacher students, and because of the teacher-directed, large group lecture-style delivery mode. However, this perception is only based on anecdotal evidence. Secondly, following their leading a programme of professional development on the change process with 30 of the 37 SOE staff, Strachan and Yates (2006) reported that the staff had collectively signalled "their intention to actively pursue meaningful change" (p. 5).

Two of the team, John Beuka and Calvin Ngatulu, were part of the consultancy group at the Curriculum Development Division (CDD) for the promulgation of resources associated with the new Solomon Islands Mathematics Curriculum. Calvin became part of the team responsible for delivering the professional development that accompanied those resources. John had recently completed a postgraduate paper in mathematics education with the University of the South Pacific and this paper had broadened his approach to mathematics education at both the school-student and preservice teacher levels. The team were all experienced mathematics educators and recognised the need to engage students, and hence they were already incorporating some meaningful contexts and activities within their personal delivery of the programme. Oswald Bako was also the primary programme co-ordinator and so was able to articulate the rationale for changes at management level and pose questions associated with the overall structure of the primary programme. Hence there was readiness for change, a sense of the change process, and an understanding of global transformations in mathematics education related to developing learners' mathematical thinking and understanding, rather than learning predetermined algorithms. There was also the desire for greater engagement by students.

One aspect that was occasionally problematic was the juxtaposition of this evolving world-view of mathematics education and the desire that any new courses developed 
reflect the unique Solomon Islands context (Strachan \& Yates, 2006). While the team were able to negotiate and articulate a common version of mathematics education that wove the essential threads of both perspectives, there were times when a tension was evident between preparing students for participation in assessment particular to a global version of mathematics and mathematics that enabled Solomon Islanders to be discriminating citizens in their own context. For instance, understanding standard measurements, and using them accurately, is important in the local trading context, but rates of change aren't. Yet rates of change underpin abstract calculus ideas used in secondary school mathematics and professions that use applied mathematics. The SOE team felt it was essential to include rates of change so as not to limit students' opportunities to engage in mathematics beyond the local setting. Discourses associated with power and colonisation underpinned some of this perspective (Thaman, 2003), while the cultural discourses associated with gender equity (Akao, 2008) were also influential. There was nevertheless consensus that giving Solomon Islanders the opportunity to participate in the global perspective of mathematics was a critical element of the programmes.

This article describes the change process and how it evolved. It considers the influences that shaped the changes and the influence of the changes. It also reflects on their sustainability. As such, it is a case study of a small-scale pedagogical change in a Pacific Island setting. But first, the literature that underpins key elements of the process is examined.

\section{Literature review}

An examination of the literature related to educational development processes in Pacific Island nations reveals several consistent themes. As early as 1994, educationalists involved in curriculum and programme development were promoting the notion of a cooperative approach to projects, with partnerships that value the contribution of all partners and where mutual benefits are expected (Baumgart, 1994). Others have proposed that sustainability will emerge from collaborative approaches (Thomas, 2002), while Crossley (1990) suggested that collaborative research gave more insightful perspectives and reduced dependence on outside agencies. Including the traditional educational approaches is also promoted as a way to create empowerment and helps lead to culturally suitable education approaches (Coxon \& Munce, 2008). Others have likewise identified the desirability of appropriate cultural contexts that reflect local traditions and ways of knowing (Bishop, 2010; Burnett, 2002; Thaman, 2003). Thaman (2003) and Puamau (2006) warn of the pervasive colonial discourse that can influence approaches, resources and assessment.

As identified through the development process involving the SOE mathematics team, there are external and local imperatives essential to a mathematics education programme. For example, local stakeholders, including students, wanted the opportunity to engage in international perspectives and assessments so as to engage and participate in the international community. So while there is recognition of the need to incorporate localised Pacific knowledge so that effective change can occur (Henly, 2005; Huffer \& Qalo, 2004; Nabolo, 2000), Puamau (2006) advocates an approach that meshes the best of local and external approaches with the learning contextualised for local settings. Nabolo-Baba (2006) likewise promoted the notion of the integration of these two influences. This concurs with discussion of development in general; that it 
should be socially just and equitable and reflect the local Pacific culture (King, 2008). There can be differences between mathematical practices in the home and at school. Owens and Kaleva (2007) reported, for instance, that in some Papua New Guinea settings quantities were measured using visual referents and with consideration given to the cultural context, rather than using standard measures only. They recommended that incorporating this ethno-mathematical practice was valuable in the teaching of measurement. However, Barton (2004) contends that care needs to be taken when labelling cultural practices as mathematics. He stated that the knowledge needed to be systemised and engaged with out of its context to be considered mathematics. $\mathrm{He}$ suggested it "should relate to quantity, relationships, or space" (p. 23). Bakalevu (2003), when reporting on the ways Fijians do mathematics, contends that Fijian ethnomathematics, including ways of quantifying, needs to be integrated with the more global versions. She also advocates that co-operative approaches and active learning be part of programmes for effective learning. These approaches were central to the version the team considered would enhance the localised approach, while simultaneously they resonate with changes in the global version of mathematics education.

Caution is required, however, in curriculum or programme change when teacher voice is marginalised. Cavanagh (2006), reporting on curriculum change in New South Wales, acknowledges the benefits of focusing on processes such as problem-solving, mathematical modelling, generalisation, communication and the justification of conjectures or informal theories. However, Cavanagh warned that teachers must see the need for change if changes are to be taken up in the first instance, and sustained in the second. Lamb and Spry (2009) reported a similar situation with change to a more investigative, learner-centred approach in Queensland. Meanwhile, reporting on the development of learner-centred educational practices in Malawi, Mtika and Gates (2010) warned of a disjuncture between learner-centred approaches and local social traditions that jeopardised their uptake by teachers, especially if appropriate resources weren't available either.

The need to build genuine relationships based on mutual respect is another central foundation on which a partnership should be built (Sanga, 2003; van Peer, 2007). Sanga also emphasised the effect of collaborative dialogue and that active engagement and leadership is required for a sense of autonomy to emerge. Others contend that for autonomy to develop, educational change must be context sensitive (Dawson, 2005). Meanwhile, using authentic learning contexts and acculturating teachers into an eclectic view of ways of learning and understanding is seen as a way of cultivating learners that participate both in local and national life and fostering critical thinking (Koya-Vaka'uta, 2002). Thus, the mathematics team looked at ways to foster authentic, respectful relationships and trust through genuine interaction through the development of the new courses with the support of Nigel. A co-constructive approach was taken to the change process with the courses and resources reflecting a mixture of local traditional pedagogy and international perspectives.

\section{The process of transition}

Aspects identified in preliminary visits and ongoing dialogue between the respective partners' management teams initiated the process of reviewing the mathematics courses. The SOE mathematics team had recognised a need for the review and potential modification of the courses they taught before Nigel arrived, and had indicated they 
would like to examine some alternative resources. The initial emphasis was on developing working relationships, so that trust and more authentic relationships could evolve. Email contact was established, which, coupled with reports from the preliminary visits, revealed some starting points for the initial meeting in Honiara. Nigel also sought out a range of what he anticipated would be appropriate resources, and compiled some professional development material around activities that used a variety of contexts appropriate for Pacific Island settings. This included some games and activities that were successful across a range of international situations, and some new material to contribute to the team that he had expertise in i.e., using digital technology. Nigel worked in the Solomon Islands as part of the SOE mathematics team on four occasions during 2007/8, with the last two visits also having a focus on assessment across the whole school. John visited the University of Waikato, both the Hamilton and Tauranga campuses, to explore mathematics education and generic aspects of the overall qualifications. There has been intermittent, although at times unreliable, ongoing email contact between the Solomon Islands team and Nigel over the last four years. The description of the process is viewed through the following three themes: the collaborative approach, the integration of Solomon Islands mathematics with the globalised version of mathematics education, and building relationships. Data collected as part of student and staff feedback is also considered.

\section{A collaborative approach}

From the outset, a collaborative approach was envisaged by both sides of the partnership as the most productive way to review the mathematics programmes. Both partners recognised each side brought strengths to the partnership. Working collaboratively would most likely produce the best outcome for the students. There were other benefits, as outlined in the literature, that suggested a collaborative methodology would enhance effectiveness and be more likely to be sustainable. Given the time and resourcing constraints of the partnership, it also seemed the most efficient way forward. At the first meeting, informal protocols regarding the way the team would work together were established, with some specifically articulated and others more implicit. These were: that any recommendations that arose out of the review process were to be approached in an open way; that there was a willingness to consider innovative ideas, to take risks, knowing that some ideas might eventually be discarded; that all contributions were to be valued and considered; and finally, that decisions were to be made by consensus whenever possible. However, at times a smaller group did make a particular decision. This may be attributed to workload or compliance aspects within the team, but also reflected the growing trust that emerged as relationships developed. Individual team members' strengths and interests were identified i.e., John with statistics, Oswald with measurement, Calvin with geometry, Joseph with number, Nigel with algebra. At the same time, the team utilised experience and expertise with particular pedagogical aspects e.g., John with group work, Joseph with games, Oswald with planning, Calvin with problem-solving, and Nigel with formative assessment. These individual strengths provided some leadership within the team. There were also pairs or groupings that had worked collaboratively on parts of the programme or external projects in the past, so it was important to build on those professional partnerships. Individual workload was identified as an issue, so consideration needed to 
be given to collaborative delivery of the programme, utilising team member strengths whenever possible.

The SOE team outlined the existing programmes, their reservations about them, what they considered were strengths (both of the programme and themselves) and ways they thought the courses might be developed. They identified the over-emphasis on content, the transmission delivery method, lack of resources (including readings), too many modules (leading to workload issues for staff and students), an over-emphasis on testing and formal, summative assessment, and the need for a more cohesive approach to pedagogy as areas they wanted to address. At the managerial level, decisions were made that also impacted on the process of transformation. For instance, developing the Teachers in Training (TIT) Certificate in Teaching for practising unqualified teachers had now become the immediate imperative, giving the opportunity for the diploma courses to reflect and build on this course. The proposed degree would likewise reflect and build on the diploma programme. As well, after some consultation, the time allowance for each course was prescribed, so a key parameter for the new course was determined.

Nigel was tasked with the co-ordinating role, and although all team members could contribute in autonomous ways, the team confirmed that John, the Head of Department, was the conduit for communication for the SOE team. This was especially important when members were dispersed to different locations or focused on other responsibilities. John also perceived it as a key component of his leadership role and with regards to external communication had the most familiarity with the Internet and email. These were identified as being central to ongoing communication with Nigel between his visits. A draft programme format was negotiated and agreed to by the team. The team decided that a draft programme for the TIT primary mathematics course would be constructed. This was considered and reviewed at a team meeting at the end of the week. It proved to be a very productive way of working collaboratively and reaching consensus, given the time constraints on individual team members. In subsequent visits, the team decided that less emphasis be put on individual meetings and more on group or whole team meetings. This again can be partly attributed to the growing relationships that were emerging through the ongoing interaction.

At the second whole team meeting, the structure of the programme was decided for the initial 10-day TIT course. Each day was to begin with a one-hour principal lecture led by one staff member, followed by a three-hour small group tutorial that focused on key elements of the lecture in a practical, activity-based approach. All staff members would lead one of these. The students would then have individual study tasks that integrated with the day's programme, but were also part of the assessment. Team responsibilities and tasks were collaboratively negotiated, building on individual strengths and interests, but with some consideration of the requirement to cover all elements of the emerging programme. This was a critical aspect of the collaborative approach as it meant all team members took leadership of areas that they felt confident with and that others recognised their expertise in. This didn't detract from team engagement in all elements of the programme, but it meant that after a team discussion and input, someone took responsibility for the detail of the course (in conjunction with the co-ordinator), the delivery of the principal lecture in that particular aspect, the organisation of the activities and resources for the tutorials, the individual study tasks, and any associated readings and assessment. This structure and approach, as well as 
being overtly collaborative, meant that members of the mathematics team could informally collaborate, report, negotiate and evaluate the course in an ongoing way. Input and self-assessment of these processes was also undertaken at team meetings to ensure individuals in the team were comfortable with the approach being taken. In this way, it was considered that overall, a genuine co-construction of the programme evolved.

Further collaboration occurred through the relationship between the team and the Curriculum Development Division (CDD). The advisory role to CDD of SOE staff meant that mutual understandings emerged. The CDD curriculum material in ongoing development reflected the approach the SOE were taking, while the new programme integrated the CDD resources. A collaborative approach to delivery ensued with a CDD staff member participating in the delivery of the new SOE programme to the teachersin-training, and SOE staff members involved in presenting professional development about the CDD resources in schools. One of the art lecturers in an adjoining office became involved and also temporarily became part of the teaching team.

Another aspect related to the collaborative approach was the professional development that was undertaken, usually at the team meetings. This aspect fits best under the relationship-building theme, so it will be addressed in that section. The next theme that emerged was the integration of Solomon Islands mathematics with the globalised version of mathematics education.

\section{The blending of local and global perspectives}

The SOE mathematics education team expressed with both clarity and unity the desire for the programme to resonate with international perspectives of both mathematics and mathematics education. While they all felt it was essential that it reflected a Solomon Islands view of mathematics and traditional pedagogy, they were clear that education in general was a means for the Solomon Islanders to connect and interact with the rest of the world, as well as it being for the development of thinking and understanding. Education was also perceived as being linked to the economic and ethical well-being of individuals, communities and the Solomon Islands. To attend secondary school or tertiary education was an aspiration for many Solomon Islanders-for themselves, their extended families, and members of their local community. An argument could be presented that this reflects the influence of an underlying colonisation discourse as is presented in the literature review, but that is not the purpose of this article. While the influence of that discourse cannot be ignored, the SOE mathematics team felt it was essential to have the programme include key international mathematical concepts. This was confirmed with management, who endorsed the inclusion. As well, student feedback on the new course, while very positive about the emphasis on pedagogy, included some comment regarding having further units on curriculum content for those who did not have the background knowledge. This indicates that this is something they value. Again, there are underlying discourses to do with colonisation that might underpin their rationale, but the perspective still reflected a community expectation that an international view of mathematics was not only desirable, but also essential. Hence the programme included content on number, measurement (including time and money), geometry, statistics, and algebraic thinking.

International perspectives on mathematics education contend that local context should also be an essential element of the programme and so the team looked to mesh 
the two in a pragmatic way that compromised neither as much as possible. This was done through situating content and learning situations in local contexts, including Solomon Islands mathematics in appropriate places, and basing pedagogy on international research, while drawing on traditional learning methods and local cultural dimensions. The Solomon Islands mathematics team already incorporated many examples of local contexts in their teaching programmes. For example, the mathematics in the outdoors unit incorporated number, measurement and geometry elements set in local situations. It also included traditional counting and recording methods, with traditional arts and crafts as the context for geometry and measurement tasks. As well, the approach taken encouraged the students to participate in co-operative group work, hence leading them to engage in active learning experiences. These incorporated aspects of both traditional and contemporary international pedagogy in mathematics.

These two pedagogical aspects were also incorporated as foci that sat alongside the content areas in the course. For instance, the first day of the Primary Mathematics course, the 5-credit course that built on the earlier 10-credit Learning and Teaching Mathematics course, has Standards 1-6 Number as the content area and Games (using games to support learning) as the pedagogical emphasis. Games had been introduced in an earlier course, which encouraged interactive, group activities centred on the communication of mathematical ideas. Local games were also included in this part of the programme and the teachers-in-training were encouraged to include their traditional games in the units of work they developed for their own classrooms.

Local environmental materials were also included in the course, demonstrating their use as a general principle of all mathematics programmes. For instance, one session included the global mathematics strategy of moving from counting all to counting on. This requires counting equipment and in Western settings would typically use plastic counters. For this activity, the students had to use seeds collected from within the SOE campus. They also had to create an equipment kit as part of the course. Shells, seeds, and other local environmental resources became an integral part of that.

Problem-solving tasks and investigations designed to foster mathematical thinking rather than just having students learning set algorithms were also set in authentic local contexts. For example, developing algebraic thinking through generalising patterns incorporated the rich Solomon Islands heritage of weaving and carving. Both traditional and contemporary Solomon Islands imagery is suitable for that purpose. It became difficult with some of the problem situations for the senior secondary course related to calculus, but this is true in most international settings where teachers and resource developers attempt to locate problems in realistic contexts. In general, although there is often a tension between local and global versions of mathematics education, there was consensus in the team that the course reflected an appropriate integration of the two perspectives.

\section{Building relationships}

The collaborative approach, which evolved further through the mathematics education team partnership, and the blending of local and international perspectives, enriched the relationships both within the SOE team and with Nigel. As discussed, the literature contends that building genuine relationships built on mutual respect is essential for partnerships to work. It is also a central element for autonomy to emerge and to allow members of the team to take leadership of their areas of responsibility, as well as the 
programme overall. Initially, Nigel made a conscious attempt to instigate positive relationships with the SOE team. This was done through organising a comprehensive range of resources for the team, as they had indicated would be valuable in the familiarisation visit, organising professional development sessions in areas that they indicated would be of value, and bringing resources that he had expertise in, with associated professional development sessions that would enhance their overall expertise. For this Nigel was able to secure a graphics calculator for each of the mathematics team and took them through a professional development programme that he used with teachers in New Zealand. Although it is unlikely that these would become part of the programme in the short term, it was nevertheless something that he considered would enhance their overall perspective of mathematics education, and enabled them to be familiar with a contemporary international approach.

The professional development sessions, which at times included input and leadership from all members of the team, were invaluable in developing the working relationship and deepening the trust between team members. The games and interactive activities were especially effective in developing team humour and camaraderie, which emerged through friendly competitiveness and banter. This also enabled inclusiveness and mutual respect to evolve as various team members worked co-operatively to solve problems or activities, took the lead in situations or experienced success. As the partnership evolved, all members of the team instigated and led these shared activities and experiences. Approaches and games were shared, and these, and Solomon Islands contexts, became effective resources for Nigel's teaching in New Zealand.

Other aspects that helped build relationships were the sharing of meals, the sharing of stories and interests from our own local contexts, and members of the Solomon Islands team assisting with suggestions for local resources and arrangements for school visits and weekend excursions. They also gave plenty of advice about sharks and crocodiles! There was also a collaborative approach taken to finding appropriate readings, discussion of qualification pathways, and collaborative research and writing. We now consider some of the other feedback that informed the ongoing course development.

\section{Staff and student feedback}

Students completed a feedback form from the teachers in training (TIT) mathematics courses that helped inform the subsequent development of the diploma mathematics courses. This was a series of questions regarding the nature of the course and the increased emphasis on activity, group work, and reflection on the learning process. It also included questions on the appropriateness of the assessments and the relevance of the course for their classroom teaching. The students completed it at the end of the course. As well, students and staff gave informal oral feedback, and two of the staff completed written feedback. The following section summarises those responses. All staff reported that the course had gone particularly well. The teachers-in-training were engaged throughout, enjoyed the emphasis on pedagogy as well as content, and were very positive about the course and its outcomes in terms of their learning and development as educators. All respondents expressed that they felt more confident about teaching mathematics after completing the course. Some felt there should be more units with an emphasis on content. This is probably due to the wide variation of conceptual knowledge. The transitioning of the course into the diploma programme 
allowed much more time and greater flexibility to include more content, and allow some differentiation of the learning to address individual preferences without compromising the emphasis on pedagogy. The staff gained affirmation for the changes through the positive feedback and the obvious increase in engagement and enthusiasm. They were confident the changes were appropriate and sustainable.

The written responses recorded that the collaborative approach to delivery and having fewer content modules eased staff workload issues and gave them time for effective interaction and dialogue with the students. Having fewer face-to-face classes also gave them more time to plan and prepare for the principal lectures and tutorials. Conversely, the tutorials provided extra challenge in finding and preparing appropriate activities "that were student-centred and interesting". The lecturers also commented that smaller tutorials made more time and opportunity available "for micro-teaching and allowed for discussion and collaboration through group work". Another response was that the self-learning modules meant that the "teacher trainees [learnt] not to rely heavily on prepared materials from the curriculum development centre". One of the lecturers commented:

Having the course reader and other relevant recommended readings allow[ed] students time to read. [Allowed the students the opportunity to do professional reading.] This is not in previous courses. The readings and related questions assist students to carry out mini research, which is a good skill for them.

This indicates the beginnings of an important transition, with the expectation changing from one of being very teacher directed to one where the students were taking responsibility for their own professional learning. Another staff member commented that "the new programme encourages a lot more teamwork, collaboration and inquiry for both students and lecturers". This likewise mentions student inquiry, but also resonates with the discussion on the enhancement of collaboration within the team.

One of the SOE staff recorded that they thought a consequence of the changes was that it would lead to " teachers of quality in the Solomon Islands". While it is a bit too early to analyse that claim, it nevertheless emphasises that they felt the changes had led to positive outcomes for the students. The other lecturer wrote: "I have learnt a lot myself over the two years and have increased my capacity as a mathematics education lecturer." Again, this gestures towards the benefits of a collaborative approach and the thinking that has occurred for the team as well as the students. Nigel also expressed that he had learnt much and had developed personally as a mathematics educator.

\section{Some implications to consider}

Generally, the new mathematics programme that evolved through co-construction was considered by the team to be positive and effective. There was enhanced engagement by students and staff; the students reported on the effectiveness of the approach and its applicability to learning in the classroom. Staff commented on an increase in student self-reflection. While the courses are embedded to some extent and staff and students were positive about the transition to a new approach, sustainability can only be measured or considered after a longer period of time has elapsed. Workload pressures and external stresses can lead to practitioners reverting to the simplest and most habitual form of delivery, which in the case of the Solomon Islands lecturers is a 
transmission approach. For a variety of reasons, there is movement by SOE staff, including going overseas to complete higher qualifications, so whether the new mathematics programme is sustainable over changes of personnel is yet to be tested. Review processes, while recommended, have not been embedded. These will be essential for ongoing sustainability so that staff critically reflect on the programme and the courses evolve in response to that reflection.

How the changes impact on teacher practice and student learning is also something that should be considered in the future, perhaps through a research study. It will be more problematic for the teachers-in-training and those who move to teach in isolated rural settings to maintain the transformation of practice. Perhaps refresher courses (with qualification papers attached) or professional development in situ would help address this isolation. Maintaining the quality of the resources is another issue linked to sustainability. These were to be centrally located and accessed from the library, but due to industrial action and then ongoing issues, they were still not completely categorised and accessible for all staff and students by the end of 2009, even though the SOE had them in boxes for some time before that. Fortunately, this has since been remedied.

The dilemma between local education imperatives and the globalisation of education is still something that requires ongoing consideration. While some of the literature (for example, Puamau, 2006) advocates for an integration of the local and international perspectives, to what extent the team got this right is still to be determined. It certainly was an aspect that was central to the transformation process they undertook. Allied to that concern is the perception that Solomon Islanders are an homogonous group. In fact, the Solomon Islanders consist of a range of people with varying cultural perspectives and languages, and differences can be marked between neighbouring islands. So to locate a mathematical problem in a Solomon Islands context or use some Solomon Islands mathematics may enhance the learning opportunities for some Solomon Islanders, but may also constrain others.

The issue of gender equity is not addressed adequately in these changes. While it has been argued that having a more eclectic approach to assessment, including more collaborative tasks, and giving greater primacy to communication is conducive to greater participation by girls and women in Western settings, these conjectures can't be transposed directly to the Solomon Islands situation. These practices may encourage greater female participation, but they may be neutral or constraining. Again, research needs to be undertaken to determine ways that gender inequity in education participation can be addressed in Pacific Island nations. We suspect it is a far more complex issue than can be addressed through curriculum or programme modification.

Teacher voice in curriculum development and educational change is also an element frequently mentioned in the literature (Lamb \& Spry, 2009). Teachers were not direct participants in the change process, although their views were considered and the teachers-in-training were surveyed for their perspectives. This may have ramifications for the influence of the changes on classroom practice.

Several of these implications are broad in nature and could be considered beyond the constraints of the task undertaken. They are part of the rich milieu of what constitutes education, though, and help inform our overall understanding of mathematics education as manifest in a Pacific Island setting. It is important to remember that given the constraints within which this process was undertaken, the transition to a new approach was successful for both the students and staff involved. Some very positive outcomes 
are already evident, so the situation has been enhanced at least in the short term, and opportunity has been given to sustain long-term benefits for the pre-service students and the children under their care.

\section{References}

Akao, S. (2008). Women's education in the Solomon Islands. On Campus With Women, 37(2). Available at http://www.aacu.org/ocww/volume37 2/global.cfm

Bakalevu, S. (2003). Ways of mathematising in Fijian society. In K.Thaman (Ed.), Educational ideas from Oceania: Selected readings (pp. 61-71). Suva, Fiji: The Institute of Education, University of the South Pacific.

Barton, B. (2004). Mathematics and mathematical practices: Where to draw the line? For the Learning of Mathematics, 24(1), 22-24.

Baumgart, N. (1994). Primary and secondary education for development: Key decision areas. In P. Hughes \& W. Renwick (Eds.), Issues in education in Asia and the Pacific: An international perspective; Conference Proceedings (pp. 95-104). Paris, France: OECD.

Bishop, R. (2010). International commentary on "Family obligations in Micronesian cultures: Implications for educators". Journal of Qualitative Studies in Education, 23(6), 691-698.

Burnett, G. (2002). Technologies and discourses of colonialism in education in the Republic of Kiribati. Directions: Journal of Educational Studies, 24(2), 10-23.

Cavanagh, M. (2006). Mathematics teachers and working mathematically: Responses to curriculum change. In P. Grootenboer, R. Zevenbergen, \& M. Chinnappan (Eds.), Mathematics education research: Innovation, networking, opportunity: Proceedings of the 29th annual conference of the Mathematics Education Research Group of Australasia (Vol. 1). Sydney, NSW, Australia: MERGA.

Coxon, E., \& Munce, K. (2008). The global education agenda and the delivery of aid to Pacific education. Comparative Education, 44(2), 147-165.

Crossley, M. (1990). Collaborative research, ethnography and comparative and international education in the South Pacific. International Journal of Educational Development, 10(1), 37-46.

Dawson, G. (2005, July). Lessons learned from the curriculum reform implementation project. Paper presented at the Papua New Guinea National Reform Curriculum Conference, Port Moresby, Papua New Guinea.

Henly, J. (2005). The primary education improvement project of Vanuatu: A model for teacher development in the Pacific. Directions: Journal of Educational Studies, 27(2), 25-36.

Huffer, E., \& Qalo. R. (2004). Have we been thinking upside-down? The contemporary emergence of Pacific theoretical thought. The Contemporary Pacific, 16(1) 87116.

King, T. (2008). Theory after the hegemony: From postdevelopment to neodevelopment. In A. Thornton \& A. McGregor (Eds.), Southern perspectives on development: Dialogue or division? Proceedings of the Fifth Biennial Conference of the Aotearoa/New Zealand International Development Studies Network (DEVNET) (pp. 141-150). Dunedin, New Zealand: University of Otago.

Koya-Vaka'uta. C. F. (2002). Weaving rainbows in Oceania: Multiculturalism in Pacific Education. Directions: Journal of Educational Studies, 2(2), 24-39. 
Lamb, J., \& Spry, G. (2009). Leading change in mathematics: The Queensland mathematics syllabus. In R. Hunter, B. Bicknell, \& T. Burgess (Eds.), Crossing divides: Proceedings of the 32nd annual conference of the Mathematics Education Research Group of Australasia (Vol. 1). Palmerston North, New Zealand: MERGA.

Mtika, P., \& Gates, P. (2010). Developing learner-centred education among secondary trainee teachers in Malawi: The dilemma of appropriation and application. International Journal of Educational Development, 30, 396-404.

Nabolo, U. (2000). Incorporating local knowledge in teaching about education and society: A Fiji case study. Suva, Fiji: Institute of Education, The University of the South Pacific.

Nabobo-Baba, U. (2006). Teacher education for new times reconceptualising pedagogy and learning in the Pacific. Directions: Journal of Educational Studies, 28(1\&2), 63-91.

Owens, K., \& Kaleva, W. (2007). Changing our perspective on measurement: A cultural case study. In J. Watson \& K. Beswick (Eds.), Mathematics: Essential research, essential practice; Proceedings of the 30th annual conference of the Mathematics Education Group of Australasia, Hobart (Vol. 2, pp. 571-580). Adelaide, SA, Australia: MERGA.

Puamau, P. (2006). Teacher education at the crossroads: Which path should we take? Directions: Journal of Educational Studies, 28(1\&2), 56-62.

Sanga, K. (2003). A context sensitive approach to educational aid. Directions: Journal of Educational Studies, 25(1 \&2), 28-39.

Strachan, J., \& Yates, R. (2006). Solomon Islands School of Education Support Partner Institution 3 Years: Familiarisation visit. Report. Hamilton, New Zealand: University of Waikato.

Thaman, K. H. (2003). Decolonizing Pacific studies: Indigenous perspectives, knowledge, and wisdom in higher education. The Contemporary Pacific, 15(1) $1-17$.

Thomas, P. (2002). Towards better practice. In D. Storey, J. Overton, \& B. Nowak (Eds.), Contesting development: Pathways to better practice. Palmerston North, New Zealand: Institute of Development Studies, Massey University.

Van Peer, L. (2007). Beyond participation: Rethinking Pacific Education Initiative-An exemplar for future development practice? (Unpublished master's thesis). Victoria University, Wellington, New Zealand.

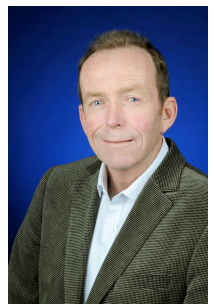

Nigel Calder is a Mathematics Education lecturer for the Faculty of Education, University of Waikato, Tauranga. He is also the Partnership and Liaison Manager for the Tauranga campus. His teaching and research interests include algebra, using digital technologies in mathematics, problem solving, mathematical thinking, and geometry. He was involved in the Partnership over several years particularly in the development of the primary and secondary Mathematics Education courses, but also facilitating professional development on formative assessment with Partnership staff. 


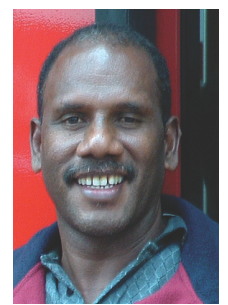

John Beuka is the head of mathematics department, School of Education at the Solomon Islands College of Higher Education (SICHE), a position he has held since 2004. He obtained a diploma in Teaching (mathematics) from SICHE, a Bachelor of Education in Mathematics and a Postgraduate Diploma in Education from the University of the South Pacific. Prior to Joining SICHE, John was principal of a community high school for 5 years.

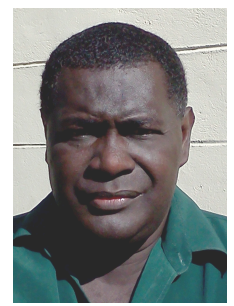

Calvin Ngatulu is a lecturer in mathematics education School of Education at the Solomon Islands College of Higher Education a position he has held since 1994. He obtained his Diploma in Education (mathematics) from Pacific Adventist University. Calvin has been teaching mathematics education for both the primary and secondary teacher education programmes. 